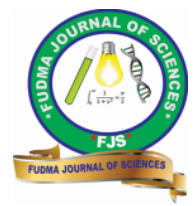

FUDMA Journal of Sciences (FJS)

ISSN online: $2616-1370$

ISSN print: 2645 - 2944

Vol. 4 No. 3, September, 2020, pp 631-635

DOI: https://doi.org/10.33003/fjs-2020-0403-293

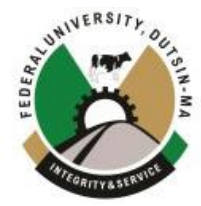

\title{
A FRAMEWORK FOR DATA INTELLIGENCE AND ITS APPLICABILITY IN EDUCATIONAL SYSTEM
}

\author{
${ }^{1}$ Esther S. Alu, *2 Joshua Abah \& ${ }^{3}$ Adewumi O. David \\ ${ }^{1}$ Faculty of Agriculture, Nasarawa State University, Lafia, Nasarawa State, Nigeria \\ ${ }^{2}$ Department of Computer Science, Federal University, Lafia, Naasarawa State, Nigeria \\ ${ }^{3}$ Department of Computer Science, Nasarawa State University, Keffi, Nasarawa State, Nigeria \\ ${ }^{*}$ Corresponding Author's Email: abah@unimaid.edu.ng
}

\begin{abstract}
Data as well as information is the most valuable tools used for academic effectiveness and for the organization to achieve its aim and objectives. Data is very essential and the cognitive means to collect and organize this data cannot be achieved without human intelligence. In the contemporary society, the means for reliability, accuracy, effectiveness and for a better recognition of an organization has to do with the reliable information and the means to which data can be collected and organized for future use and for the effective management of the organization. Data intelligence guarantees the integral and sustainable development in all aspect of human endeavors; Science and Technologyy, Arts and Humanities and in every other aspect of human development, data intelligence serves as the master key for decision making. This paper critically reviews the necessity of data intelligence and its application areas in harmony with the effectiveness of academic and educational institutions. This work concludes that data intelligence is integral to the effectiveness of any organization including educational institutions and no organizational problem can be tackled without data intelligence. It is recommended that data intelligence should be applied in the Nigeria educational system and machine learning techniques be applied so as to derive meaning from available data banks. This work developed a framework for application of data intelligence in educational system.
\end{abstract}

Keywords: Academic effectiveness, decision making, data intelligence, educational development, machine learning.

\section{INTRODUCTION}

The development of data transformation or change has brought about new development and transformation into the globe with many businesses becoming more data oriented thereby not only transforming data into wealth but also advanced the use of data in decision-making. Many big organizations such as academic or educational institution have been transformed not only through data utilization for information management but also manipulated data into innovation which has helped in classroom teaching either by physical or digital.

With the advent of artificial intelligence, big data, data mining, machine learning and business intelligence, the availability of data and its effective utilization has become the center-point of academic and educational advancement and its means of transformation through technological advancement through the use of information technology.

The formation of data intelligence cannot be achieved without the co-integration of Artificial Intelligence (AI), Data Mining and Machine Learning (ML). Data Intelligence is the combination of AI and ML and has become the assurance of future creativity (sisense.com).

\section{Concept of Data Intelligence in Education}

Data intelligence is the collaboration and analysis of diverse data configuration into meaningful ways so as to provide insight for the organizational decision making and future development (sisense.com). With big data needed to be consumed for different types of investigation and analysis, data intelligence is an extension to the traditional way in which data are seen and digested. The Combination of Artificial Intelligence and Machine Learning provides organizations with the ability to analyze massive datasets much more reliably and noticeably faster. More so, the data is arranged by established models for storing datasets of that size. These datasets provide insights that help organizations discover and develop new opportunities via the marketplace.

Today, about $30 \%$ of the students in Nigerian Universities are at risk of being left behind as a result of inadequate learning skills and improper management decision making (Uwezo, 2016). Non fair access to education contribute to the problem, even with the availability of the top management team, the organization of the institution could not be achieved due to inadequate decision making or poor management ability as a result of non-availability of data (Education Commission, 2016). These are common challenges across the globe especially Nigeria. According to the International Commission on Financing Global Education Opportunity (Education Commission, 2016), only one in ten children in low-income countries (four in ten in middle-income countries) are on track to gain basic educational skills by 2030 . However, the problem of learning excessively affect marginalized populations; children in poor households or rural areas (especially girls), children with disabilities, and children affected by conflict and violence. In addition, the provision for good management decision making and proper data utilization should be put in place in the Nigeria education system.

It is understood that the status quo is not good enough and more has to be done. While belligerent schools would certainly 
gain from better facilities and more teachers, research emphasizes that input-oriented solutions are not enough (World Bank, 2018). Many institutions that have possessions to learning still fall short of adequate resources. However, relatively resource-poor education systems in Nigeria, for example, hit above their weight in achieving greater gains for students than their peers with similar income levels (World Bank, 2018).Parents, teachers, policymakers, and school administrators need better tools or equipment as well as resources to identify where and why learning gaps exist, and assess what strategies they can apply to improve the situation. And that is why data intelligence is needed to improve the organization and academic standard in terms of decision making and standard of learning in Nigerian educational institutions.Several governments, organizations, and companies have drawn their attention to this challenge and are generating high amounts of data and analysis to support education decision-making around the world. Yet, large gaps remain, as data management processes at the school and national level are often under-funded, ad hoc, and of variable quality and timeliness.

This paper aims at helping the Nigerian education system to look at what information or data decision-makers need for results oriented and managee change. In Nigerian education institutions especially Universities, the means to manage and utilize data in order to ease the business of an organization has become one of the major problems facing the education system. It is believed that most secondary schools and some reasonable number of Nigerian universities are still operating in the old or manual system of data flow which has the capability of revealing or exposing some meaningful information. With the idea of data intelligence, this paper provides a review of the role data intelligence in the industries and educational institution in particular.

\section{REVIEW OF LITERATURE}

According to Alex (2008), in 1990s, school managements, teachers, parents, stakeholders and policy-makers started looking toward quantitative data as an essential tool for decisions making and policy implementation, articulating analyses about strengths and weaknesses of institutions, and evaluating the effects of initiatives and policies thereby ensuring the necessity of data intelligence in the education system.

(Baker \& Yacef, 2009; Koedinger, D'Mello, McLaughlin, Pardos, \& Rosé, 2015) said recently, one of the first developed areas of research that has worked to systematically use the power of quantitative analyses in the field of education has been the field of Educational Data Mining (EDM). Moreover, the further introduction of data intelligence will go a long way not only solving the problem of the existing system of data mining but will improve the academic standard of teaching and learning, it shall also improve management capabilities after the experimentation in business and other sectors such as ICT. Seen from an institutional perspective, one general characteristic of educational data analytics and Learning Analytics (LA) in particular is that the effort traditionally made by individual teachers or specific groups of teachers, that is, the use of data for improving educational experiences and results, is now made systematic at the organizational level (Bowers, 2017; Bowers, et al., 2016). In other terms, it is no more the single responsibility of individuals in schools to use quantitative evidence for rethinking and redesigning didactic activities and interventions (Cosner, 2014; FarleyRipple \& Buttram, 2015; Schildkamp, Poortman, \& I Handelzalts, 2016), as the recent research argues that data analytics is also an institution's task and, of course, the tools that an institution can use for this aim are much more powerful than those in the hands of volunteer teachers and assistants (Bowers et al., 2014).

In such perspective, the first aim of an analyst who wants to apply data mining to education is to collect raw data about the educational activities and processes (at individual, organizational and the system level) that have no sense if read without a theoretical background as a lens (Bowers, Krumm, Feng, \& Podkul, 2016). Such an effort has been traditionally very strong, because of the way that data are stored in the educational institutions; namely, following administrative rules and procedures, and with little use of technology (Cho \& Wayman, 2015). Things are changing rapidly, and today many schooling datasets are huge, well-classified, readily available, and much diversified (Behrens \& DiCerbo, 2014; Bowers, 2017; Bowers, Shoho, \& Barnett, 2014; Feng, Krumm, Bowers, \& Podkul, 2016; Koedinger et al., 2010). This evolution has been immediately caught by researchers, and applications of sophisticated data mining style analyses to those datasets have generated a rich stream of academic papers, reports, and practical applications (Baker \&Inventado, 2014). In a first stage, then, the research aimed at mainly finding important and frequent recurrences and patterns in available data, something that users of this information usually do not pursue (Bienkowski, Feng, \& Means, 2012). However, opportunities offered by developments in statistics, operations research and information and communication technologies (ICT) are today further empowering the potential of data analysis, by moving towards more sophisticated approaches that are classified under the name of "analytics".

Following the above statement, researchers today have gone far in developing those sophisticated data applications which has the capability of using both audio and video call but none of the application is $70 \%$ students/teachers oriented. $65 \%$ of the academic staff cannot apply some of these applications such as google classroom or zoom for effective teaching because of the ineffectiveness of those applications. Developing a standard classroom oriented model using data intelligence thatat will be user-friendly and also have interactive features will serve as solution to these problem.

One of the challenges in this type of model development, as well as in other areas of education research, is limited access to training data. For example, while a system might be used by hundreds of thousands of students, it could be impractical to obtain training labels of affect (often collected by expert field observers) or data on long-term outcomes, for more than a few hundred or few thousand students. As such, collecting representative data becomes essential, as does paying attention to validation methods that inform developers about whether a model is representative, such as conducting population-level cross-validation on a diverse sample of students. By taking 
these steps, it becomes possible to increase confidence that the resulting models will be relevant for the full population of students where the model's predictions would be useful. (Baker \& Yacef, 2009).

Another trend that still needs to be developed is the actual use of these types of detectors in intelligent educational systems of various sorts. There are far more published examples of detectors than there are of detectors being used to drive intervention, though some positive examples do exist. In perhaps the most notable example, the Purdue Signals Project (now Ellucian) provided instructors with reports of whether students were at risk of dropping or failing a course, and scaffold instructors in how to intervene, leading to better outcomes for learners. Examples also exist in fully automated systems. Carnegie Learning has been leveraging automated models of student knowledge using data mining methods to tailor the quantity of instruction students receive on different topics, leading to positive learning outcomes. More complex models have also been used in automated systems, but only with relatively small-scale studies in classrooms and laboratory settings. These systems have found benefits from automated agents that adapt to disengagement and affect, but these approaches have not yet been deployed at scale (Baker et al., 2013).

As stressed by Campbell \& Oblinger (2007, p. 42) in their seminal study on Academic Analytic, this can be "...thought as the practice of mining institutional data to produce 'actionable intelligence." Thus, here the role of school principals and managers; more than teachers is at the heart of the use of results. In one meaning suggested by Goldstein
(2005), Academic Analytics can also be intended as the systematic use of data for generating suggestions aimed at improving the internal efficiency of educational institutions' operations and managerial processes (that is, personnel management, procurement, etc.). This can also be achieved through the development of academic learning software thereby using data coding to improve student academic standard and learning capacity.

\section{METHODOLOGY}

For an accurate data collection and for effective management and decision making, there is need for planning, which has to do with the involvement of data intelligence to be adopted as the new system. However, the development and adoption of the new system will go a long way to;

i. Solve the problem of data redundancy in the existing system;

ii. Help management take decision based on the available data that will be collected.

The development of data intelligence in educational institutions demands the need for the management to understand the scientific research findings and incorporate them in every day decision making in the system. The methodology could be in three ways which are Structured System Analysis and Design Methodology (SSADM), Rapid Application Development (RAD) method and the Object Oriented Method (OOM) but with the contest of this paper, the researchers suggests the adoption of the Object Oriented Method because it does not necessarily need an application to be developed. However, it involved the development of a computer system on a component bases which guaranteed the reuse of the existing system by sharing the same with the available resources.
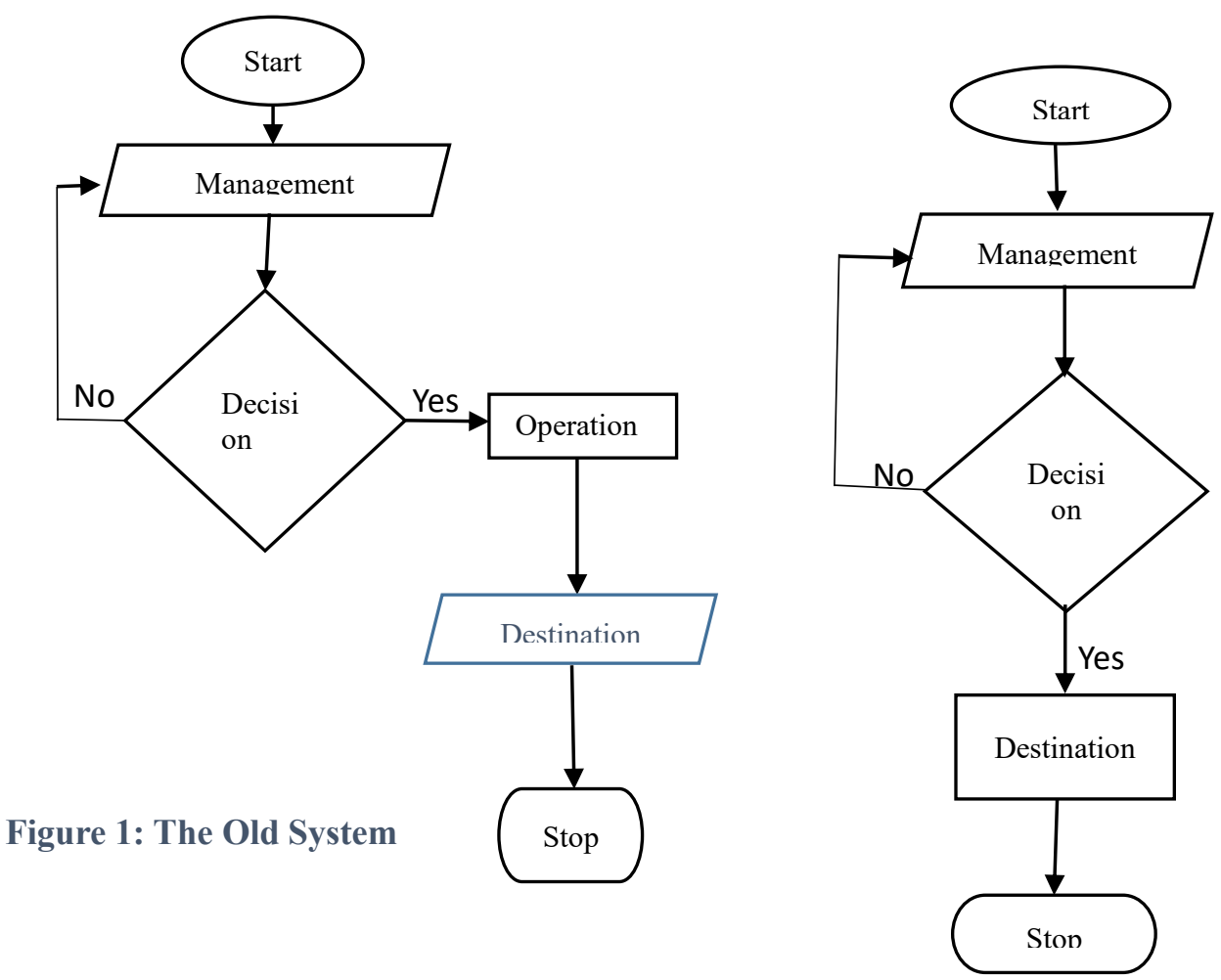

Figure 2: The New System 
Figure 1 shows the flow of data from management which is the decision maker through the operational staff to the destination. With the explanation of the flowchart in figure 1, it has the tendency of exposing some vital information from one person to the order before getting to the destination because the information cannot move directly from the source to the destination thereby coursing data redundancy. It also shows that there is no data integrity in the existing system.

\section{Significance of the New System}

Figure 2 shows the movement of information from the source to the destination without any interference of the third party. This could be noticed in the elimination of the operational processes that constitutes bottleneck to free flow of data. It ensures there is data integrity as well as data security, it encourages the use of big data or artificial intelligence in the education system. Data integrity is an attribute of database management system by which every information belonging to any organization is confidential. In data integrity, there is no provision for the third party to know the content or the secret of the organization except the one authorized by the management to be made public.

\section{CONCLUSION}

Data intelligence is the collaboration and analysis of diverse data configuration into meaningful ways so as to provide insight for the organizational decision making and future development. Adopting the idea of data intelligence in Nigeria educational system and institutions will help in harmonizing and improving the teaching standard and also help in management decision making. This is applicable both in business and every other aspect of human endeavors.

\section{RECOMMENDATIONS AND FUTURE RESEARCH}

It is recommended that data intelligence should be applied in the Nigeria educational system and in the contest of this research, that further improvement be made by adopting Machine Learning models in developing a standard prediction software that could provide information that aids management and teachers in their decision to improve performance and reduce mass failure of students due to teaching lapses and lack of standard decision making procedure for the overall improvement of education in Nigeria in particular and the world at large.

\section{REFERENCES}

Agasisti, T., Bowers, A.J. (2017). Data Analytics and Decision Making in Education: Towards the Educational Data Scientist as a Key Actor in Schools and Higher Education Institutions.

Johnes, G., Johnes, J., Agasisti, T., López-Torres, L. (Eds.) Handbook of Contemporary Education Economics (p.184210). Cheltenham, UK: Edward Elgar Publishing. ISBN: 978178536-906-3 http:/www.e-elgar.com/shop/handbookofcontemporary-education-economics

Baker, R.S.J.D. et al., (2009) "Educational Software Features that Encourage and Discourage 'Gaming the System'," Proc. 14thInt'l Conf. Artificial Intelligence in Education, 2009, pp. 475-482.

Baker, R.S., \& Inventado, P.S. (2014). 'Educational data mining and learning analytics'. In J.A. Larusson \& B. White (Eds.), Learning Analytics pp. 61-75. New York: Springer.

Baker, R.S., \& Yacef, K. (2009). 'The State of Educational
Data Mining in 2009: A Review and Future Visions'. Journal of Educational Data Mining, 1(1), 3-16.

Baker R. \&Yacef, K., (2009). "The State of Educational Data Mining in 2009: A Review and Future Visions," J. Educational Data Mining, vol. 1, no. 1, 2009, pp. 3-17.

Baker, R.S.J.D. et al., (2013) "Predicting Robust Learning with the Visual Form of the Moment-by-Moment Learning Curve," J.Learning Sciences, vol. 22, no. 4, 2013, pp. 639-666.

Balfanz, R., Herzog, L., \& MacIver, D. J. (2007). 'Preventing student disengagement and keeping students on the graduation path in urban middle-grades schools: Early identification and effective interventions'. Educational Psychologist, 42(4), 223235.

Behrens, J. T., \& DiCerbo, K. E. (2014). Technological Implications for Assessment Ecosystems: Opportunities for Digital Technology to Advance Assessment. Teachers College Record, 116(11), 1-22.

Bienkowski, M., Feng, M., \& Means, B. (2012). 'Enhancing Teaching and Learning through Educational Data Mining and Learning Analytics: An Issue Brief'. Washington, DC: U.S. Department of Education, Office of Educational Technology.

Bowers, A.J., Krumm, A.E., Feng, M., \& Podkul, T. (2016). 'Building a Data Analytics Partnership to Inform School Leadership Evidence-Based Improvement Cycles'. Paper presented at the Annual meeting of the American Educational Research Association, Washington, DC.

Bowers, A.J. (2017). 'Quantitative Research Methods Training in Education Leadership and Administration Preparation Programs as Disciplined Inquiry for Building School Improvement Capacity. Journal of Research on Leadership Education, 12(1), pp.72-96. http://doi.org/10.1177/1942775116659462.

Bowers, A.J., Shoho, A.R., \& Barnett, B.G. (2014). 'Considering the Use of Data by School Leaders for Decision Making'. In A.J. Bowers, A.R. Shoho \& B.G. Barnett (Eds.), Using Data in Schools to Inform Leadership and Decision Making. pp. 1-16. Charlotte, NC: Information Age Publishing.

Bouwma-Gearhart, J., \& Collins, J. (2015, October). 'What We Know About Data-Driven Decision Making In Higher Education: Informing Educational Policy and Practice'. In Proceedings of International Academic Conferences No. 2805154. International Institute of Social and Economic Sciences.

Bowers, A.J. (2008). 'Promoting Excellence: Good to great, NYC's district 2, and the case of a high performing school district'. Leadership and Policy in Schools, 7(2), 154-177. 
Bowers, A. J., Shoho, A. R., \& Barnett, B. G. (2014) 'Considering the Use of Data by School Leaders for Decision Making'. In A. J. Bowers, A. R. Shoho \& B. G. Barnett (Eds.), Using Data in Schools to Inform Leadership and Decision Making. pp. 1-16. Charlotte, NC: Information Age Publishing.

Bowers, A.J., Sprott, R., \& Taff, S. (2013). 'Do we know who will drop out? A review of the predictors of dropping out of high school: Precision, sensitivity and specificity'. The High School Journal, 96(2), 77-100.

Braun, M.L., \& Ong, C.S. (2014). 'Open Science in Machine Learning'. In V. Stodde, F. Leisch \& R. D. Peng (Eds.), Implementing Reproducible Research. pp. 343365: Chapman and Hall/CRC.

Brunello, G., \& Checchi, D. (2007). 'Does school tracking affect equality of opportunity? New international evidence'. Economic Policy, 22(52), 782-861.

Campbell, J. P., \& Oblinger, D. G. (2007). 'Academic analytics'. EDUCAUSE Review, 42(4), 40-57.

Cosner, S. (2014). 'Strengthening Collaborative Practices in Schools: The Need to Cultivate Development

Daniel, B. (2015). 'Big Data and analytics in higher education: Opportunities and challenges'. British Journal of Educational Technology, 46(5), 904-920. Datnow, A., \& Hubbard, L. (2015). 'Teachers' Use of Assessment Data to Inform Instruction: Lessons from the Past and Prospects for the Future'. Teachers College Record, 117(4), 1-26.
Farley-Ripple, E.N., \& Buttram, J.L. (2015). 'The Development of Capacity for Data Use: The Role of Teacher Networks in an Elementary School'. Teachers College Record, 117(4), 1-34

Gandomi, A., \& Haider, M. (2015). 'Beyond the hype: Big data concepts, methods, and analytics'. International Journal of Information Management, 35(2), 137-144.

Perspectives and Diagnostic Approaches'. In A. J. Bowers, A. R. Shoho \& B. G. Barnett (Eds.), Using Data in Schools to Inform Leadership and Decision Making. Charlotte, NC: Information Age Publishing.

Schutt, R., \& O'Neil, C. (2013). Doing Data Science: Straight Talk from the Frontline. Cambridge, MA:

Uwezo. 2016. Are Our Children Learning? Uwezo Uganda 6th Learning Assessment Report. Kampala: Twaweza East Africa.

World Bank. 2018. World Development Report 2018: Learning to Realize Education's Promise. Washington, DC: World Bank.

https://www.researchgate.net/publication/322447978_Data_An alytics and Decision-

making in Education Towards the Educational Data Scienti st as a Key Actor in Schools and Higher Education Institutions/link/5a593645 aca2727d60815f64/download

https://www.sisense.com/glossary/data-intelligence/ 